\title{
Advantages of McKeown minimally invasive oesophagectomy for the treatment of oesophageal cancer: propensity score matching analysis of 169 cases
}

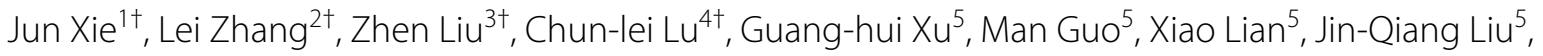
Hong-Wei Zhang ${ }^{4^{*}}$ (D) and Shi-ying Zheng ${ }^{1 *}$

\begin{abstract}
Background: Oesophagectomy, the gold standard for oesophageal cancer treatment, causes significantly high morbidity and mortality. McKeown minimally invasive oesophagectomy (MIE) is preferred for treating oesophageal malignancies; however, limited studies with large sample sizes focusing on the surgical and oncological outcomes of this procedure have been reported. We aimed to compare the clinical safety and efficacy of McKeown MIE with those of open oesophagectomy (OE).
\end{abstract}

Patients and methods: Overall, 338 oesophageal cancer patients matched by gender, age, location, size, and T and N stages (McKeown MIE: 169 vs OE: 169) were analysed. The clinicopathologic features, operational factors, postoperative complications, and prognoses were compared between the groups.

Results: McKeown MIE resulted in less bleeding (200 mL vs $300 \mathrm{~mL}, p<0.01)$, longer operation time (335.0 h vs 240.0 $h, p<0.01$ ), and higher number of harvested lymph nodes (22 vs $9, p<0.01$ ) than OE did. Although the rate of recurrent laryngeal nerve injury in the two groups was not significantly different, incidence of anastomotic leakage (8 vs 24 , $p=0.003$ ) was significantly lower in the McKeown MIE group. In addition, patients who underwent McKeown MIE had higher 5-year overall survival than those who underwent OE (69.9\% vs 40.4\%, $p<0.001)$.

Conclusion: McKeown MIE is proved to be feasible and safe to achieve better surgical and oncological outcomes for oesophageal cancer compared with OE.

Keywords: Oesophageal cancer, McKeown MIE, Open oesophagectomy, Prognosis

*Correspondence: zhanghwfmmu@126.com; syzheng571025@163.com †Jun Xie, Lei Zhang, Zhen Liu and Chun-lei Lu contributed equally to this work.

${ }^{1}$ Department of Thoracic Surgery, The First Affiliated Hospital of Soochow University, Shizi Street No. 188, Suzhou 215006, Jiangsu, China

${ }^{4}$ Digestive Diseases Center of Wuxi Mingci Hospital, No. 599 Zhongnan Road, Jinxing Street, Wuxi City 214000, Jiangsu Province, China

Full list of author information is available at the end of the article

\section{Background}

Oesophageal cancer (EC) is the sixth-leading cause of cancer-related death globally [1] and China is among the countries facing the highest risk of EC [2]. The mortality of EC in China is the highest in the world, with an incidence of 16.7 per 100,000 person-years and a death rate of 13.4 per 100,000 person-years [3]. For resectable EC, oesophagectomy combined with chemoradiotherapy remains the mainstay of multimodality treatment [4-8]. 
Open oesophagectomy (OE) is correlated with remarkably high rates of morbidity and mortality during the perioperative period and is considered as one of the most traumatic and extensive surgeries in cancer [9]. Therefore, with the development of minimally invasive technique $[10,11]$, McKeown minimally invasive oesophagectomy (MIE), which was first reported in 2000 and achieved similar or better clinical outcomes compared with $\mathrm{OE}$ [12], has become increasingly popular and is favourably performed at most academic centres. To date, several studies that compared the outcomes of OE and MIE have been published. Most of them reported that MIE reduced the surgical access-related trauma, which resulted in shorter hospitalisation and lower rates of respiratory complications and wound infections [13-17].

However, the surgical and oncological outcomes of MIE remain controversial. Nonrandomised studies have shown patients treated with MIE have lower rates of major complications than those treated with $\mathrm{OE}[16,18$, 19]. Only one RCT enrolling 115 patients from five centres in the Netherlands reported that MIE was associated with a low rate of pulmonary infection, but it lacked the power to detect any oncologic difference [20]. In addition, a large systematic review concluded that the actual benefits of MIE over OE remain unclear in terms of short and long-term outcomes [21]. The cervical anastomosis performed in McKeown MIE is an invasive procedure associated with a high risk of injury in the recurrent laryngeal nerve (RLN) and anastomotic leakage [22], although cervical fistula remains a manageable complication in case of leakage [23]. In addition, none of the studies above used a median follow-up time $>40$ months $[15$, 24-29].

Therefore, the current study aimed to compare the surgical and oncological outcomes in patients with EC who underwent OE or McKeown MIE performed in two independent centres, respectively.

\section{Patients and methods}

This retrospective study has been approved by the Xijing Hospital Ethics Committee in compliance with the ethical principles stated by the Declaration of Helsinki. From August 2010 to December 2014, 463 EC patients who underwent McKeown MIE in Xijing Hospital and 169 EC patients who underwent OE in the First Affiliated Hospital of Soochow University were retrospectively included.

The eligibility criteria were as follows: (1) diagnosis confirmed by oesophagoscopy and pathology of the biopsies; (2) underwent oesophagectomy (McKeown MIE or $\mathrm{OE})$; (3) without pre-operative neoadjuvant chemotherapy and/or radiotherapy; (4) clinical T1-3N0-1M0 stage; (5) respiratory function tolerability under doublelung ventilation for thoracotomy operation; and (6) no previous thoracic, hiatal, or bariatric surgery. Exclusion criteria were as follows: (1) underwent palliative resection and (2) incomplete records. Surgeons in both centres were experienced in $\mathrm{OE}$, and those performing McKeown MIE were required to have done at least $40 \mathrm{McK}$ eown MIEs owing to the learning curve of the procedure.

The 463 patients who underwent McKeown MIE were matched with 169 patients who underwent OE using a 1:1 propensity score matching (PSM) by gender, age, tumour location and size, and $\mathrm{T}$ and $\mathrm{N}$ stage. After the matching, a total of 338 EC patients (McKeown MIE: 169 vs OE: 169$)$ were included.

The 169 patients in the McKeown MIE group received cervical anastomosis and omentoplasty while patients in the OE group received intrathoracic anastomosis. The gastric tube for substitution was used for all the patients in the McKeown MIE group and the entire stomach for substitution was performed in the OE group.

\section{Postoperative follow-up}

Patients were followed up from the first month when discharged, and every three months in the following two years, then every 6 months by outpatient service via telephone as per National Comprehensive Cancer Network guidelines [30].

\section{Data collection}

Preoperative data including gender, age, preoperative smoking history, tumour site, preoperative diet, and comorbidities were prospectively collected. Blood loss and operative time were recorded as intraoperative data. Postoperative data included histologic type, tumour size, tumour invasion, lymph node metastasis, harvested lymph nodes, postoperative hospitalisation, R0 resections, reoperation, length of intensive care unit stay, complications, and in-hospital/30-day death. The TNM stage was defined according to the 7th edition of the AJCC Staging Manual.

\section{Statistical analyses}

The abnormally distributed continuous variables were expressed as median value (interquartile range) and categorical variables were expressed as numbers (percentages). PSM was performed using the $\mathrm{R}$ software (3.6.1) with Package MatchIt (version 4.1.0) to adjust for confounding variables including sex, age, location, size, and $\mathrm{T}$ and $\mathrm{N}$ stage between patients who underwent McKeown MIE and OE [31]. The abnormally distributed continuous variables were compared using Mann-Whitney $U$ test. The categorical variables were compared using $X^{2}$ test or Fisher's exact test. Survival curves were drawn using Kaplan-Meier methods and compared using the log-rank test. A two-tailed $p$ value 
less than 0.05 was considered statistically significant. The data were analysed using the SPSS software (version 16.0, Chicago, IL).

\section{Results}

From August 2010 to December 2014, 632 EC patients received oesophagectomy at two independent centres. Of them, 463 underwent McKeown MIE and 169 underwent OE. After PSM by gender, age, location, size, and $\mathrm{T}$ and $\mathrm{N}$ stage, a total of $338 \mathrm{EC}$ patients with matched pairs (McKeown MIE: 169 versus OE: 169) were included. Clinical and pathological features of the enrolled patients are summarised in Table 1.

EC was diagnosed and confirmed by two experienced pathologists. Of the 169 cases, 162 cases in the McKeown MIE group and 148 in the OE group were squamous cell carcinoma. The remaining were cases of adenocarcinoma (3), adenosquamous carcinoma (3), and small cell carcinomas (1) in the McKeown MIE group and adenocarcinomas (10), adenosquamous carcinomas (5), neuroendocrine carcinoma (2), small cell carcinoma (2), and sarcomas (2) in the OE group. Postoperative histologic features and tumour size had no significant difference between patients in the two groups (Table 2).

McKeown MIE was related with less bleeding $(200 \mathrm{~mL}$ vs $300 \mathrm{~mL}, p<0.01$ ), more harvested lymph nodes ( $22 \mathrm{vs}$ $9, p<0.01)$ but longer operation time $(335.0 \mathrm{~h}$ vs $240.0 \mathrm{~h}$, $p<0.01)$ than those of OE (Table 3). In addition, no difference was found regarding the rate of metastatic lymph nodes as well as the number of reoperations between the two groups. All of the patients underwent R0 resection (Table 3).

As shown in Table 4 for the postoperative complications, there were no intra-operative death cases in either group. McKeown MIE was significantly associated with lower rates of minor complications and major complications compared with OE (minor: $13.0 \%$ vs $22.5 \%$, $p=0.023$; major: $17.8 \%$ vs $27.8 \%, p=0.028$ ). Less patients who underwent McKeown MIE experienced pneumonia (5 vs $17, p=0.008)$ and anastomotic leakage ( 8 vs 24 , $p=0.003)$ postoperatively than those who underwent OE. Patients in the McKeown MIE group also had shorter hospitalisation ( 10 days vs 12 days, $p<0.01$ ) and a trend of less in-hospital/30-day mortality ( 2 vs $8, p=0.054$ ). Other complications showed no significant difference between the two groups ( $p>0.05$, Table 4 ).

The range of follow-up was 15-74 months. As shown in Fig. 1, patients who underwent McKeown MIE had higher 1/3/5-year OS than those underwent OE (1-year: $94 \%$ vs $75.5 \%$; 3 -year: $78.5 \%$ vs $52.7 \%$; 5 -year: $69.9 \%$ vs $40.4 \%$, all $p<0.001)$.
Table 1 Clinical characteristics of the patients with oesophageal cancer

\begin{tabular}{|c|c|c|c|}
\hline $\begin{array}{l}\text { Clinical } \\
\text { characteristics }\end{array}$ & MIE group $(n=169)$ & OE group $(n=169)$ & $P$ \\
\hline Sex & & & 0.804 \\
\hline Male & $126(74.6 \%)$ & $124(73.4 \%)$ & \\
\hline Female & $43(25.4 \%)$ & $45(26.6 \%)$ & \\
\hline Age & & & 0.229 \\
\hline$\leq 49$ & $16(9.5 \%)$ & $13(7.7 \%)$ & \\
\hline $50-59$ & $46(27.2 \%)$ & $47(27.8 \%)$ & \\
\hline $60-69$ & $89(52.7 \%)$ & $78(46.2 \%)$ & \\
\hline $70-79$ & $18(10.7 \%)$ & $29(17.2 \%)$ & \\
\hline$\geq 80$ & $0(0.0 \%)$ & $2(1.2 \%)$ & \\
\hline Preoperative smoker & & & 0.446 \\
\hline Yes & $79(46.7 \%)$ & $86(50.9 \%)$ & \\
\hline No & $90(53.3 \%)$ & $83(49.1 \%)$ & \\
\hline Tumour location (\%) & & & 0.967 \\
\hline Upper & $16(9.5 \%)$ & $17(10.1 \%)$ & \\
\hline Mid & $90(53.3 \%)$ & 91 (53.8\%) & \\
\hline Lower & $63(37.3 \%)$ & $61(36.1 \%)$ & \\
\hline Preoperative diet & & & 0.109 \\
\hline Solid & $24(14.2 \%)$ & $20(11.8 \%)$ & \\
\hline Semi-liquid & $84(49.7 \%)$ & $96(56.8 \%)$ & \\
\hline Total liquid & $36(21.3 \%)$ & $41(24.3 \%)$ & \\
\hline Water & $25(14.8 \%)$ & $12(7.1 \%)$ & \\
\hline Comorbidity & 37 (21.9\%) & $28(16.6 \%)$ & 0.214 \\
\hline Hypertension & $16(9.5 \%)$ & $11(6.5 \%)$ & 0.316 \\
\hline Diabetes & $6(3.6 \%)$ & $7(4.1 \%)$ & 0.777 \\
\hline $\begin{array}{l}\text { Coronary artery } \\
\text { disease }\end{array}$ & $5(3.0 \%)$ & $4(2.4 \%)$ & 1.000 \\
\hline COPD & $7(4.1 \%)$ & $4(2.4 \%)$ & 0.358 \\
\hline Arrhythmia & $2(1.2 \%)$ & $2(1.2 \%)$ & 0.174 \\
\hline Liver cirrhosis & $1(0.6 \%)$ & $0(0.0 \%)$ & 1.000 \\
\hline
\end{tabular}

COPD chronic obstructive pulmonary disease

\section{Discussion}

In the current study, we found that McKeown MIE resulted in less bleeding, longer operative time, shorter postoperative hospitalisation, and showed a trend of lower in-hospital/30-day mortality than $\mathrm{OE}$ did. Although the rate of RLN injury was comparable between the two groups, lower incidences of postoperative pneumonia and anastomotic leakage have been observed in patients who underwent McKeown MIE. In addition, McKeown MIE was related to more harvested lymph nodes and improved survival compared with OE. The present study showed that McKeown MIE was safe and feasible for EC with similar or better surgical and oncological outcomes compared with OE.

Radical oesophagectomy is generally accepted as a standard surgical procedure for resectable EC. MIE 
Table 2 Surgical and postoperative pathologic information of the patients with oesophageal cancer

\begin{tabular}{|c|c|c|c|}
\hline Clinical variables & MIE group $(n=169)$ & OE group $(n=169)$ & $P$ \\
\hline Substitution type & & & $<0.01$ \\
\hline Entire stomach & 0 & $169(100 \%)$ & \\
\hline Gastric tube & $169(100 \%)$ & 0 & \\
\hline Anastomotic type & & & $<0.01$ \\
\hline Cervical anastomosis & $169(100 \%)$ & 0 & \\
\hline Intrathoracic anastomosis & 0 & $169(100 \%)$ & \\
\hline Omentoplasty & & & $<0.01$ \\
\hline Yes & $169(100 \%)$ & 0 & \\
\hline No & 0 & $169(100 \%)$ & \\
\hline Histologic type & & & 0.100 \\
\hline Squamous cell carcinoma & $162(95.9 \%)$ & $148(87.6 \%)$ & \\
\hline Adenocarcinoma & $3(1.8 \%)$ & $10(5.9 \%)$ & \\
\hline Adenosquamous carcinoma & $3(1.8 \%)$ & $5(3.0 \%)$ & \\
\hline Neuroendocrine carcinoma & $0(0.0 \%)$ & $2(1.2 \%)$ & \\
\hline Small cell carcinoma & $1(0.6 \%)$ & $2(1.2 \%)$ & \\
\hline Sarcoma & $0(0.0 \%)$ & $2(1.2 \%)$ & \\
\hline Tumour size (mean $\pm \mathrm{SD}, \mathrm{cm}$ ) & $4.78 \pm 2.17$ & $4.80 \pm 2.05$ & 0.879 \\
\hline T stage & & & 0.314 \\
\hline $\mathrm{T} 1$ & $21(12.4 \%)$ & $20(11.8 \%)$ & \\
\hline $\mathrm{T} 2$ & $47(27.8 \%)$ & 49 (29.0\%) & \\
\hline T3 & $100(59.2 \%)$ & $82(48.5 \%)$ & \\
\hline T4 & $1(0.6 \%)$ & $18(10.7 \%)$ & \\
\hline N stage & & & 0.974 \\
\hline No & $105(62.1 \%)$ & 104 (61.5\%) & \\
\hline $\mathrm{N} 1$ & $53(31.4 \%)$ & 54 (32.0\%) & \\
\hline N2 & $7(4.1 \%)$ & $8(4.7 \%)$ & \\
\hline N3 & $4(2.4 \%)$ & $3(1.8 \%)$ & \\
\hline
\end{tabular}

Table 3 Surgical outcomes of the patients with oesophageal cancer

\begin{tabular}{|c|c|c|c|}
\hline Clinical variables & MIE group $(n=169)$ & OE group $(n=169)$ & $P$ \\
\hline Blood loss (median, IQR, ml) & $200.0(150.0,300.0)$ & $300.0(250.0,450.0)$ & $<0.01$ \\
\hline Operative time (median, IQR, min) & $335.0(280.0,385.0)$ & $240.0(185.0,285.0)$ & $<0.01$ \\
\hline \multicolumn{4}{|l|}{ Lymph nodes harvested } \\
\hline Median (IQR) & $22(17,30)$ & $9(6,15)$ & $<0.01$ \\
\hline Mean \pm SD & $24.5 \pm 10.0$ & $11.2 \pm 7.9$ & $<0.01$ \\
\hline \multicolumn{4}{|l|}{ Number of metastasis nodes } \\
\hline Median (IQR) & $0(0,1.0)$ & $0(0,1.0)$ & 0.730 \\
\hline Mean \pm SD & $1.2 \pm 3.2$ & $0.98 \pm 2.0$ & 0.406 \\
\hline Rate of metastasis nodes & 64 (37.9\%) & 67 (40.9\%) & 0.577 \\
\hline RO resections & $169(100 \%)$ & 169 (100\%) & 1.000 \\
\hline Reoperation & $2(50.0 \%)$ & $2(50.0 \%)$ & 1.000 \\
\hline
\end{tabular}

was introduced to decrease the significant perioperative morbidity and mortality caused by OE [12, 32]. Several previous studies have demonstrated that MIE could significantly improve perioperative outcomes of EC; however, limitations existed in some of them, such as selection bias and data heterogeneity [22, 33-35]. The only level I evidence came from a recent multicentre randomised clinical trial [36-38]. These reports identified 
Table 4 Complications of the patients with oesophageal cancer

\begin{tabular}{llll}
\hline Complications & MIE group $(\boldsymbol{n}=\mathbf{1 6 9 )}$ & OE group $(\boldsymbol{n}=\mathbf{1 6 9 )}$ & $\boldsymbol{P}$ \\
\hline Minor complication & $22(13.0 \%)$ & $38(22.5 \%)$ & 0.023 \\
Pneumothorax & $5(3.0 \%)$ & $8(4.7 \%)$ & 0.396 \\
Atelectasis & $6(3.6 \%)$ & $5(3.0 \%)$ & 0.759 \\
Pneumonia & $5(3.0 \%)$ & $17(10.1 \%)$ & 0.008 \\
Arrhythmia & $4(2.4 \%)$ & $3(1.8 \%)$ & $5(3.0 \%)$ \\
Wound infection & $2(1.2 \%)$ & $47(27.8 \%)$ & 1.000 \\
Major complication & $30(17.8 \%)$ & $6(3.6 \%)$ & 0.448 \\
Pneumonia & $2(1.2 \%)$ & $4(2.4 \%)$ & 0.028 \\
RLN injury & $4(2.4 \%)$ & $2(1.2 \%)$ & 0.283 \\
Chylothorax & $3(1.8 \%)$ & $24(14.2 \%)$ & 0.638 \\
Anastomotic leakage & $8(4.7 \%)$ & $3(1.8 \%)$ & 1.000 \\
Delayed gastric emptying & $4(2.4 \%)$ & $3(1.8 \%)$ & 0.003 \\
Tracheo-bronchial injury & $0(0.0 \%)$ & $3(1.8 \%)$ & 1.000 \\
Anastomotic stricture & $7(4.1 \%)$ & $2(1.2 \%)$ & 0.248 \\
Respiratory failure & $2(1.2 \%)$ & $8(4.7 \%)$ & 0.199 \\
In-hospital/30-day mortality & $2(1.2 \%)$ & $12(10,15)$ & 1.000 \\
Postoperative hospitalisation (days) & $10(9,12)$ & 0.054 \\
\hline
\end{tabular}

Minor complication: Clavien-Dindo grade 1-2. Major complications: Clavien-Dindo grade 3-5

$R L N$ recurrent laryngeal nerve

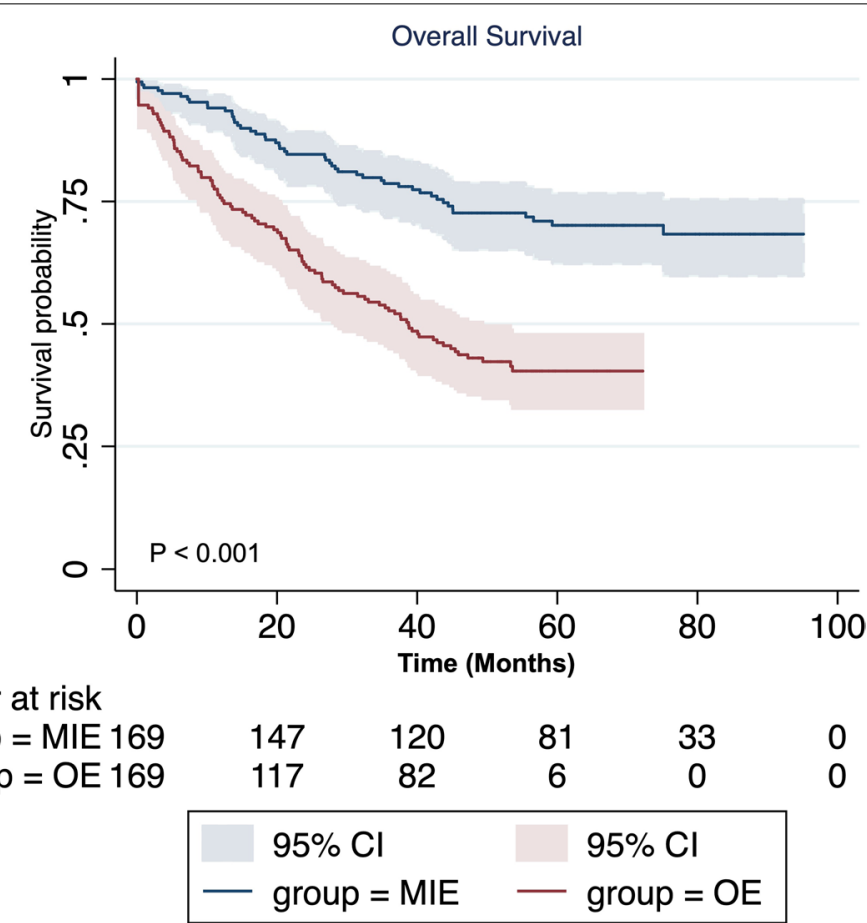

Fig. 1 Comparison of overall survival between patients who underwent McKeown minimally invasive oesophagectomy and those who underwent open oesophagectomy

that, in comparison with OE, MIE was significantly related to less bleeding, lower pulmonary infection rate, and shorter hospitalisation. The present results were consistent with previous reports $[12,18,30,39,40]$ that the blood loss was significantly decreased in the McKeown MIE group, even though the operation time was 
longer. Higher blood loss during oesophagectomy has been shown to be significantly related with the prognosis of EC [41]. Furthermore, McKeown MIE was associated with a shorter postoperative hospital stay than OE was and had a trend of lower in-hospital/30-day mortality than OE did. Meanwhile, the intra-operative morbidity and number of reoperations were comparable between these two groups. These results together suggest that McKeown MIE is a safe procedure.

The choice of incision and position are always the subject of extensive discussion for oesophagectomy. The cervical incision is necessary to create cervical oesophagogastric anastomosis and lymph node dissection during McKeown MIE. Since the chest incision in the McKeown MIE group was measured approximately $1 \mathrm{~cm}$, the disadvantages of $\mathrm{OE}$, for instance, extensive trauma, distraction of ribs, and damage of chest wall, which may lead to blood loss, can be avoided. Some surgeons choose to use Endo GIA staples to perform an intracorporeal gastric conduit $[42,43]$. In our series, a GIA linear stapler was used to perform a small abdomen incision along the lesser curvature to prepare the gastric conduit extracorporeally. There are three advantages of this approach: (1) reduction of operating costs, time, and complexity, (2) easier removal of samples, and (3) more convenient indwelling of duodenal nutrition tube or jejunum colostomy.

The left-lateral semi-prone position of McKeown MIE could be another beneficial factor. Gravity and artificial pneumothorax can spontaneously expose mediastinal organs and structures that do not need any assistance. The lung then drops off regardless of small handling. Exudates aspiration is not needed during the surgery because the fluid mainly accumulates in the right-anterior chest cavity. In addition, the neutral position of the wrists and shoulder joints of the surgeon will minimise exhaustion and maximise ergonomic function. Meanwhile, intraoperative conversion to $\mathrm{OE}$ could be conducted without re-positioning patients and losing precious time as two conversions in our series.

Postoperative morbidity is one of the most concerning problems of oesophagectomy. McKeown MIE was related to a lower rate of postoperative morbidity in the current study, which was consistent with previous reports [44, 45]. Patients who underwent McKeown MIE experienced less pneumonia and anastomotic leakage compared with those who underwent OE. One of the most important differences between the surgical techniques was that a gastric tube was used for cervical anastomosis in McKeown MIE compared with the use of the entire stomach for the thoracic anastomosis in OE. Few studies have reported that cervical anastomosis was associated with a higher anastomotic leakage rate [46-49], given that available randomised evidence is limited. In contrast, Shen et al. [50] reported that a narrow gastric tube could reduce the incidence of MIE-related anastomotic leakage because of its relative longer tube of the stomach and less interference with perfusion. The present result is consistent with that of Shen's result that less anastomotic leakage occurred following cervical anastomosis. It is noteworthy that all the patients in the MIE group received omentoplasty to cover the anastomosis which is also a possible reason to contribute to the current favourable results. A meta-analysis published on Cochrane Database Systematic Reviews [51] reported that the omentoplasty may decrease the incidence of postoperative anastomotic leakage for those who received transhiatal oesophagogastrectomy (RR: 0.23 , 95\% CI: 0.07-0.79); however, this benefit was not statistically significant on patients treated with transthoracic oesophagogastrectomy (RR: 0.19, 95\% CI:0.03-1.03) or three-field oesophagectomy (RR:0.33, 95\% CI:0.09-1.19). The role of omentoplasty on the reduction of anastomotic leakage after oesophagectomy warrants further randomised controlled trials. We also believe that it is associated with sufficient drainage, proper utilisation of antibiotics, and adequate nutritional support. Additionally, previous studies have shown that lower morbidity and mortality could be achieved because of the manageability of cervical leakage by cervical enterocutaneous fistula, compared with the thoracic anastomosis-related leakage [48]. Pleural and mediastinal infection caused by the anastomotic leakage is another risk factor for postoperative patients. In this study, three patients died of pleural mediastinal infection secondary to anastomotic leakage in the OE group.

Lymph node metastasis in the RLN region is a common progression of EC which results in poor prognosis [52]. However, both cervical lymphadenectomy and thoracoscope of McKeown MIE are believed to possibly increase the chance of RLN injury [53], resulting in the occurrence of complications and poorer survival $[54,55]$. Hence, protecting the RLN during lymph node dissection is one of the key points, while carefully identifying and preventing accidental injury. The possible injury of heat conduction of ultrasonic scalpel is also worth the attention. Lymph nodes of the bilateral RLN were dissected as a routine for all patients, and the incidence of postoperative recurrent nerve injury was comparable between the two groups. The evidence above showed a combination of thoracoscopy and laparoscopy could provide a better vision field of surgery and the vascular and lymphatic vessels can be exposed more clearly.

Several studies reported that MIE was associated with a lower pulmonary complication rate compared with $\mathrm{OE}[13,18,36,56-58]$. In a recent study, Sihag et al. [13] reported that MIE was exclusively associated 
with a significant reduction in pulmonary complications. In contrast, Smithers et al. and other researchers $[16,59]$ suggested that MIE increased the incidence of postoperative pulmonary complications, indicating that the incidence of respiratory complications may vary based on the operators' technique. In the present study, with regard to the incidence of respiratory complications, only the incidence of pneumonia (Clavien-Dindo grade $1-2$ ) was significantly reduced in the McKeown MIE group compared with the OE group. The minimal lung retraction of McKeown MIE with less injury to lung parenchyma is thought to be one of the reasons that contribute to the reduction of pneumonia incidence. Furthermore, MIE reduced damage to the muscles of the chest wall, resulting in the easy drainage of bronchial secretions and less postoperative pain.

In addition to surgical technique modification, surgeons are also interested in improving oncological outcomes after surgery. The surgical margin affects prognosis after resection of the EC [60,61]. It was initially suggested that MIE decreased the surgical margin due to the lack of palpation [41]. However, palpation probably is less important when a wide resection is planned, and it has been reported that the surgical margin and the rate of local recurrence were similar in the MIE and OE groups [62]. In the current study, all the enrolled patients underwent $\mathrm{R} 0$ resection.

Dissection of lymph nodes is another key factor for oesophagectomy due to its specific characteristics including multidirectional lymph flow and unpredictable lymphatic metastasis from cervix to abdomen [6365]. Berger et al. found that MIE harvested more lymph nodes than OE did (20 vs 9) [66], which was consistent with the present results. Based on these results, the extended radical McKeown MIE with three-field lymph node dissection is confirmed to be a preferable surgical approach. Nevertheless, while studies suggested that MIE achieved equal or better oncological efficacy [38, 67], other studies showed no significant differences in oncologic efficacy between MIE and conventional OE [28].

Thus, the long-term survival was compared between the two procedures. In this regard, patients who underwent McKeown MIE had significantly longer overall survival compared with those who underwent OE. Palazzo and colleagues [68] analysed the 5-year survival of 168 patients with EC and demonstrated the superiority of MIE (hazard ratio 2.0). A previous meta-analysis showed a comparable prognosis among MIE and other surgical methods [69]. Another retrospective study, performed recently in UK, also reported significant improvement in survival by MIE compared with that by open or hybrid procedures [39].
Several limitations exist in the current study. One was the non-randomised design and limited sample size that needs further sufficiently powered RCTs. In this study, the PSM method was adopted to adjust for the confounding variables between the two groups. Moreover, all surgical procedures in the McKeown MIE group were performed by a surgeon with advanced thoracoscopic and laparoscopic experience and expertise. Thus, the reproducibility of this study may vary based on the proficiency and experience of the surgeons who performed the procedure.

\section{Conclusion}

McKeown MIE is confirmed to be feasible and safe to achieve better surgical and oncological outcomes compared with OE. The McKeown MIE technology is superior to $\mathrm{OE}$ and is worthy of being widely applied in the treatment of EC.

\section{Abbreviations}

EC: Oesophageal cancer; OE: Open oesophagectomy; MIE: Minimally invasive oesophagectomy; RLN: Recurrent laryngeal nerve; ICU: Intensive care unit.

\section{Acknowledgements \\ Not applicable.}

\section{Authors' contributions}

Jun Xie performed surgery, collected and analysed data, drafted the manuscript. Lei Zhang collected and analysed data and drafted the manuscript. Zhen Liu performed statistical analysis. Chun-lei Lu performed surgery. Man Guo collected data. Guanghui Xu, Xiao Lian performed the statistical analysis and proofread the manuscript. Hong-wei Zhang performed surgical resection, designed and supervised this study. Shi-ying Zheng designed and supervised this study. The author(s) read and approved the final manuscript.

\section{Funding}

Wuxi Health Commission research project Fund Z202003.

Availability of data and materials

Please contact the corresponding author for data requests.

\section{Declarations}

\section{Ethics approval and consent for participate}

This retrospective study was approved by the Xijing Hospital Ethics Committee and written informed consent was obtained from the patients.

\section{Consent for publication}

The written consent is available for review by the Editor-in-Chief of this journal.

\section{Competing interests}

There are no financial or other relations that could lead to a conflict of interest.

\section{Author details}

${ }^{1}$ Department of Thoracic Surgery, The First Affiliated Hospital of Soochow University, Shizi Street No. 188, Suzhou 215006, Jiangsu, China. ${ }^{2}$ The Key Laboratory of Biomedical Information Engineering of Ministry of Education, School of Life Science and Technology, Xi'an Jiaotong University, Xi'an, Shanxi Province, China. ${ }^{3}$ Department of General Surgery, Peking Union Medical College Hospital, Chinese Academy of Medical Sciences \& Peking Union Medical College, Beijing 100730, China. ${ }^{4}$ Digestive Diseases Center of Wuxi Mingci Hospital, No. 599 Zhongnan Road, Jinxing Street, Wuxi City 214000, Jiangsu Province, China. ${ }^{5}$ Department of General Surgery, Xijing Hospital of Digestive 
Diseases, The Fourth Military Medical University, Xi'an 710033, Shan Xi Province, China.

\section{Received: 24 August 2021 Accepted: 18 February 2022}

Published online: 25 February 2022

\section{References}

1. Sihag S, Kosinski AS, Gaissert HA, et al. Minimally invasive versus open esophagectomy for esophageal cancer: a comparison of early surgical outcomes from The Society of Thoracic Surgeons National Database. Ann Thorac Surg. 2016;101(4):1281-8; discussion 88-9. https://doi.org/10. 1016/j.athoracsur.2015.09.095.

2. Bray F, Ferlay J, Soerjomataram I, et al. Global cancer statistics 2018: GLOBOCAN estimates of incidence and mortality worldwide for 36 cancers in 185 countries. CA Cancer J Clin. 2018;68(6):394-424. https://doi.org/10. 3322/caac.21492.

3. He J. Standardization of diagnosis and treatment is the only way to promote the esophageal cancer treatment and research in China. Zhonghua Zhong Liu Za Zhi. 2012;34(4):241-4. https://doi.org/10.3760/cma.j.issn. 0253-3766.2012.04.001.

4. Wu PC, Posner MC. The role of surgery in the management of oesophageal cancer. Lancet Oncol. 2003;4(8):481-8. https://doi.org/10.1016/ s1470-2045(03)01167-7.

5. Kuo YH, Chien YW, Chen PR, et al. Impact of the interval between neoadjuvant concurrent chemoradiotherapy and esophagectomy in the modern era: a population-based propensity-score-matched retrospective cohort study in Asia. World J Surg Oncol. 2019;17(1):222. https://doi.org/ 10.1186/s12957-019-1712-7 [published Online First: 20191219].

6. Li Z, Dong J, Huang Q, et al. Comparison of three digestive tract reconstruction methods for the treatment of Siewert II and III adenocarcinoma of esophagogastric junction: a prospective, randomized controlled study. World J Surg Oncol. 2019;17(1):209. https://doi.org/10.1186/s12957-0191762-x [published Online First: 20191206].

7. Kumar T, Pai E, Singh R, et al. Neoadjuvant strategies in resectable carcinoma esophagus: a meta-analysis of randomized trials. World J Surg Oncol. 2020;18(1):59. https://doi.org/10.1186/s12957-020-01830-x [published Online First: 20200321].

8. Yang P, Zhou X, Yang X, et al. Neoadjuvant camrelizumab plus chemotherapy in treating locally advanced esophageal squamous cell carcinoma patients: a pilot study. World J Surg Oncol. 2021;19(1):333. https:// doi.org/10.1186/s12957-021-02446-5 [published Online First: 20211122].

9. Fabian T, Martin JT, McKelvey AA, et al. Minimally invasive esophagectomy: a teaching hospital's first year experience. Dis Esophagus. 2008;21(3):220-5. https://doi.org/10.1111/j.1442-2050.2007.00783.x.

10. Huang Y, Liu G, Wang X, et al. Safety and feasibility of total laparoscopic radical resection of Siewert type $\|$ gastroesophageal junction adenocarcinoma through the left diaphragm and left thoracic auxiliary hole. World J Surg Oncol. 2021;19(1):73. https://doi.org/10.1186/s12957-021-02183-9 [published Online First: 20210313].

11. Pang W, Liu G, Zhang Y, et al. Total laparoscopic transabdominal-transdiaphragmatic approach for treating Siewert II tumors: a prospective analysis of a case series. World J Surg Oncol. 2021;19(1):26. https://doi. org/10.1186/s12957-021-02136-2 [published Online First: 20210123].

12. Luketich JD, Schauer PR, Christie NA, et al. Minimally invasive esophagectomy. Ann Thorac Surg. 2000;70(3):906-11; discussion 11-2. https://doi. org/10.1016/s0003-4975(00)01711-2.

13. Sihag S, Wright CD, Wain JC, et al. Comparison of perioperative outcomes following open versus minimally invasive Ivor Lewis oesophagectomy at a single, high-volume centre. Eur J Cardiothorac Surg. 2012;42(3):430-7. https://doi.org/10.1093/ejcts/ezs031.

14. Pham TH, Perry KA, Dolan JP, et al. Comparison of perioperative outcomes after combined thoracoscopic-laparoscopic esophagectomy and open Ivor-Lewis esophagectomy. Am J Surg. 2010;199(5):594-8. https://doi. org/10.1016/j.amjsurg.2010.01.005.

15. Parameswaran R, Veeramootoo D, Krishnadas R, et al. Comparative experience of open and minimally invasive esophagogastric resection. World J Surg. 2009;33(9):1868-75. https://doi.org/10.1007/s00268-009-0116-1.
16. Smithers BM, Gotley DC, Martin I, et al. Comparison of the outcomes between open and minimally invasive esophagectomy. Ann Surg. 2007;245(2):232-40. https://doi.org/10.1097/01.sla.0000225093.58071.c6.

17. Xie MR, Liu CQ, Guo MF, et al. Short-term outcomes of minimally invasive Ivor-Lewis esophagectomy for esophageal cancer. Ann Thorac Surg. 2014;97(5):1721-7. https://doi.org/10.1016/j.athoracsur.2014.01.054.

18. Luketich JD, Alvelo-Rivera M, Buenaventura PO, et al. Minimally invasive esophagectomy: outcomes in 222 patients. Ann Surg. 2003;238(4):48694; discussion 94-5. https://doi.org/10.1097/01.sla.0000089858.40725.68.

19. Berrisford RG, Wajed SA, Sanders D, et al. Short-term outcomes following total minimally invasive oesophagectomy. Br J Surg. 2008;95(5):602-10. https://doi.org/10.1002/bjs.6054.

20. Fujita $\mathrm{H}$, Kakegawa T, Yamana $\mathrm{H}$, et al. Mortality and morbidity rates, postoperative course, quality of life, and prognosis after extended radical lymphadenectomy for esophageal cancer. Comparison of threefield lymphadenectomy with two-field lymphadenectomy. Ann Surg. 1995;222(5):654-62. https://doi.org/10.1097/00000658-199511000-00008.

21. Gemmill EH, McCulloch P. Systematic review of minimally invasive resection for gastro-oesophageal cancer. Br J Surg. 2007;94(12):1461-7. https:// doi.org/10.1002/bjs.6015.

22. Luketich JD, Pennathur A, Awais O, et al. Outcomes after minimally invasive esophagectomy: review of over 1000 patients. Ann Surg. 2012;256(1):95-103. https://doi.org/10.1097/SLA.0b013e3182590603.

23. Scheepers JJ, van der Peet DL, Veenhof AA, et al. Systematic approach of postoperative gastric conduit complications after esophageal resection. Dis Esophagus. 2010;23(2):117-21. https://doi.org/10.1111/j.1442-2050. 2009.00970.x

24. Schoppmann SF, Prager G, Langer FB, et al. Open versus minimally invasive esophagectomy: a single-center case controlled study. Surg Endosc. 2010;24(12):3044-53. https://doi.org/10.1007/s00464-010-1083-1.

25. Kinjo Y, Kurita N, Nakamura F, et al. Effectiveness of combined thoracoscopic-laparoscopic esophagectomy: comparison of postoperative complications and midterm oncological outcomes in patients with esophageal cancer. Surg Endosc. 2012;26(2):381-90. https://doi.org/10. 1007/s00464-011-1883-y.

26. Singh RK, Pham TH, Diggs BS, et al. Minimally invasive esophagectomy provides equivalent oncologic outcomes to open esophagectomy for locally advanced (stage II or III) esophageal carcinoma. Arch Surg. 2011;146(6):711-4. https://doi.org/10.1001/archsurg.2011.146.

27. Sundaram A, Geronimo JC, Willer BL, et al. Survival and quality of life after minimally invasive esophagectomy: a single-surgeon experience. Surg Endosc. 2012;26(1):168-76. https://doi.org/10.1007/s00464-011-1850-7.

28. Zingg U, McQuinn A, DiValentino D, et al. Minimally invasive versus open esophagectomy for patients with esophageal cancer. Ann Thorac Surg. 2009;87(3):911-9. https://doi.org/10.1016/j.athoracsur.2008.11.060.

29. Noble F, Kelly JJ, Bailey IS, et al. A prospective comparison of totally minimally invasive versus open Ivor Lewis esophagectomy. Dis Esophagus. 2013;26(3):263-71. https://doi.org/10.1111/j.1442-2050.2012.01356.x.

30. Palazzo F, Rosato EL, Chaudhary A, et al. Minimally invasive esophagectomy provides significant survival advantage compared with open or hybrid esophagectomy for patients with cancers of the esophagus and gastroesophageal junction. J Am Coll Surg. 2015;220(4):672-9. https:// doi.org/10.1016/j.jamcollsurg.2014.12.023.

31. Ho D, Imai K, King G, et al. Matchlt: Nonparametric Preprocessing for Parametric Causal Inference. J Stat Softw. 2011;42(8):28. https://www.jstat soft.org/article/view/v042i08.

32. Shen X, Chen T, Shi X, et al. Modified reverse-puncture anastomotic technique vs. traditional technique for total minimally invasive Ivor-Lewis esophagectomy. World J Surg Oncol. 2020;18(1):325. https://doi.org/10. 1186/s12957-020-02093-2 [published Online First: 20201209].

33. Ben-David K, Rossidis G, Zlotecki RA, et al. Minimally invasive esophagectomy is safe and effective following neoadjuvant chemoradiation therapy. Ann Surg Oncol. 2011;18(12):3324-9. https://doi.org/10.1245/ s10434-011-1702-7.

34. Pennathur A, Luketich JD. Minimally invasive esophagectomy: short-term outcomes appear comparable to open esophagectomy. Ann Surg. 2012;255(2):206-7. https://doi.org/10.1097/SLA.0b013e318243308c.

35. Pang $Q$, Duan $L$, Jiang $Y$, et al. Oncologic and long-term outcomes of enhanced recovery after surgery in cancer surgeries - a systematic review. World J Surg Oncol. 2021;19(1):191. https://doi.org/10.1186/s12957-02102306-2 [published Online First: 20210629]. 
36. Biere SS, van Berge Henegouwen MI, Maas KW, et al. Minimally invasive versus open oesophagectomy for patients with oesophageal cancer: a multicentre, open-label, randomised controlled trial. Lancet. 2012;379(9829):1887-92. https://doi.org/10.1016/S0140-6736(12) 60516-9.

37. Cuesta MA, Biere SS, van Berge Henegouwen MI, et al. Randomised trial, Minimally Invasive Oesophagectomy versus open oesophagectomy for patients with resectable oesophageal cancer. J Thorac Dis. 2012;4(5):4624. https://doi.org/10.3978/j.issn.2072-1439.2012.08.12.

38. Biere SS, Maas KW, Bonavina L, et al. Traditional invasive vs. minimally invasive esophagectomy: a multi-center, randomized trial (TIME-trial). BMC Surg. 2011;11:2. https://doi.org/10.1186/1471-2482-11-2.

39. Burdall OC, Boddy AP, Fullick J, et al. A comparative study of survival after minimally invasive and open oesophagectomy. Surg Endosc. 2015;29(2):431-7. https://doi.org/10.1007/s00464-014-3694-4.

40. Kubo N, Ohira M, Yamashita Y, et al. The impact of combined thoracoscopic and laparoscopic surgery on pulmonary complications after radical esophagectomy in patients with resectable esophageal cancer. Anticancer Res. 2014;34(5):2399-404.

41. D'Journo XB, Thomas PA. Current management of esophageal cancer. J Thorac Dis. 2014;6(Suppl 2):S253-64. https://doi.org/10.3978/j.issn.20721439.2014.04.16.

42. Pennathur $A$, Awais $\mathrm{O}$, Luketich JD. Technique of minimally invasive Ivor Lewis esophagectomy. Ann Thorac Surg. 2010;89(6):S2159-62. https:// doi.org/10.1016/j.athoracsur.2010.03.069.

43. Bizekis C, Kent MS, Luketich JD, et al. Initial experience with minimally invasive Ivor Lewis esophagectomy. Ann Thorac Surg. 2006;82(2):402-6; discussion 06-7. https://doi.org/10.1016/j.athoracsur.2006.02.052.

44. Kim T, Hochwald SN, Sarosi GA, et al. Review of minimally invasive esophagectomy and current controversies. Gastroenterol Res Pract. 2012;2012:683213. https://doi.org/10.1155/2012/683213.

45. Anderegg MC, Gisbertz SS, van Berge Henegouwen MI. Minimally invasive surgery for oesophageal cancer. Best Pract Res Clin Gastroenterol. 2014;28(1):41-52. https://doi.org/10.1016/j.bpg.2013.11.002.

46. Biere SS, Maas KW, Cuesta MA, et al. Cervical or thoracic anastomosis after esophagectomy for cancer: a systematic review and meta-analysis. Dig Surg. 2011;28(1):29-35. https://doi.org/10.1159/000322014.

47. Nguyen NT, Hinojosa MW, Smith BR, et al. Minimally invasive esophagectomy: lessons learned from 104 operations. Ann Surg. 2008;248(6):108191. https://doi.org/10.1097/SLA.0b013e31818b72b5.

48. Huang HT, Wang F, Shen L, et al. Clinical Outcome of Middle Thoracic Esophageal Cancer with Intrathoracic or Cervical Anastomosis. Thorac Cardiovasc Surg. 2015;63(4):328-34. https://doi.org/10.1055/s-00341371509.

49. Shah DR, Martinez SR, Canter RJ, et al. Comparative morbidity and mortality from cervical or thoracic esophageal anastomoses. J Surg Oncol. 2013;108(7):472-6. https://doi.org/10.1002/jso.23423.

50. Shen $Y$, Wang $H$, Feng $M$, et al. The effect of narrowed gastric conduits on anastomotic leakage following minimally invasive oesophagectomy. Interact Cardiovasc Thorac Surg. 2014;19(2):263-8. https://doi.org/10. 1093/icvts/ivu151.

51. Yuan $Y$, Zeng $X$, Hu Y, et al. Omentoplasty for oesophagogastrostomy after oesophagectomy. Cochrane Database Syst Rev. 2014;(10):CD008446. https://doi.org/10.1002/14651858.CD008446.pub3.

52. Greenstein AJ, Litle VR, Swanson SJ, et al. Prognostic significance of the number of lymph node metastases in esophageal cancer. J Am Coll Surg. 2008;206(2):239-46. https://doi.org/10.1016/j.jamcollsurg.2007.09.003.

53. Zhai C, Liu Y, LiW, et al. A comparison of short-term outcomes between Ivor-Lewis and McKeown minimally invasive esophagectomy. J Thorac Dis. 2015;7(12):2352-8. https://doi.org/10.3978/j.issn.2072-1439.2015.12. 15.

54. Safranek PM, Cubitt J, Booth MI, et al. Review of open and minimal access approaches to oesophagectomy for cancer. Br J Surg. 2010;97(12):184553. https://doi.org/10.1002/bjs.7231.

55. Hulscher JB, van Sandick JW, Devriese PP, et al. Vocal cord paralysis after subtotal oesophagectomy. Br J Surg. 1999;86(12):1583-7. https://doi.org/ 10.1046/j.1365-2168.1999.01333.x.

56. Bakhos CT, Fabian T, Oyasiji TO, et al. Impact of the surgical technique on pulmonary morbidity after esophagectomy. Ann Thorac Surg. 2012;93(1):221-6; discussion 26-7. https://doi.org/10.1016/j.athoracsur. 2011.07.030.
57. Ben-David K, Sarosi GA, Cendan JC, et al. Decreasing morbidity and mortality in 100 consecutive minimally invasive esophagectomies. Surg Endosc. 2012;26(1):162-7. https://doi.org/10.1007/s00464-011-1846-3.

58. Nagpal K, Ahmed K, Vats A, et al. Is minimally invasive surgery beneficial in the management of esophageal cancer? A meta-analysis. Surg Endosc. 2010;24(7):1621-9. https://doi.org/10.1007/s00464-009-0822-7.

59. Hulscher JB, van Sandick JW, de Boer AG, et al. Extended transthoracic resection compared with limited transhiatal resection for adenocarcinoma of the esophagus. N Engl J Med. 2002;347(21):1662-9. https://doi. org/10.1056/NEJMoa022343.

60. Baba Y, Watanabe M, Yoshida N, et al. Neoadjuvant treatment for esophageal squamous cell carcinoma. World J Gastrointest Oncol. 2014;6(5):1218. https://doi.org/10.4251/wjgo.v6.i5.121.

61. Napier KJ, Scheerer M, Misra S. Esophageal cancer: A Review of epidemiology, pathogenesis, staging workup and treatment modalities. World J Gastrointest Oncol. 2014;6(5):112-20. https://doi.org/10.4251/wjgo.v6.i5. 112.

62. Wang W, Zhou Y, Feng J, et al. Oncological and surgical outcomes of minimally invasive versus open esophagectomy for esophageal squamous cell carcinoma: a matched-pair comparative study. Int J Clin Exp Med. 2015;8(9):15983-90.

63. Shimada $\mathrm{H}$, Okazumi S, Matsubara $\mathrm{H}$, et al. Impact of the number and extent of positive lymph nodes in 200 patients with thoracic esophageal squamous cell carcinoma after three-field lymph node dissection. World $\rfloor$ Surg. 2006;30(8):1441-9. https://doi.org/10.1007/s00268-005-0462-6.

64. Wakita A, Motoyama S, Sato Y, et al. Evaluation of metastatic lymph nodes in cNO thoracic esophageal cancer patients with inconsistent pathological lymph node diagnosis. World J Surg Oncol. 2020;18(1):111. https://doi. org/10.1186/s12957-020-01880-1 [published Online First: 20200529].

65. Deng XM, Zhu TY, Wang GJ, et al. Lymph node metastasis pattern and significance of left gastric artery lymph node dissection in esophagectomy for esophageal cancers. World J Surg Oncol. 2021;19(1):296. https://doi. org/10.1186/s12957-021-02405-0 [published Online First: 20211011].

66. Berger AC, Bloomenthal A, Weksler B, et al. Oncologic efficacy is not compromised, and may be improved with minimally invasive esophagectomy. J Am Coll Surg. 2011;212(4):560-6; discussion 66-8. https://doi.org/ 10.1016/j.jamcollsurg.2010.12.042.

67. Mandard AM, Dalibard F, Mandard JC, et al. Pathologic assessment of tumor regression after preoperative chemoradiotherapy of esophageal carcinoma. Clinicopathologic correlations. Cancer. 1994;73(11):2680-6 https://doi.org/10.1002/1097-0142(19940601)73:11<2680::aid-cncr2 820731105>3.0.co;2-c.

68. Zhang DW, Cheng GY, Huang GJ, et al. Operable squamous esophageal cancer: current results from the East. World J Surg. 1994;18(3):347-54. https://doi.org/10.1007/BF00316813.

69. Zhang R, Kang N, Xia W, et al. Thoracoscopic purse string technique for minimally invasive Ivor Lewis esophagectomy. J Thorac Dis. 2014;6(2):148-51. https://doi.org/10.3978/j.issn.2072-1439.2013.12.27.

\section{Publisher's Note}

Springer Nature remains neutral with regard to jurisdictional claims in published maps and institutional affiliations.

$$
\begin{aligned}
& \text { Ready to submit your research? Choose BMC and benefit from: } \\
& \text { - fast, convenient online submission } \\
& \text { - thorough peer review by experienced researchers in your field } \\
& \text { - rapid publication on acceptance } \\
& \text { - support for research data, including large and complex data types } \\
& \text { - gold Open Access which fosters wider collaboration and increased citations } \\
& \text { - maximum visibility for your research: over } 100 \mathrm{M} \text { website views per year }
\end{aligned}
$$

At BMC, research is always in progress.

Learn more biomedcentral.com/submissions 